\title{
Photoinduced 1,2,3,4-tetrahydropyridine ring conversions
}

\author{
Baiba Turovska*1, Henning Lund ${ }^{2}$, Viesturs Lūsis ${ }^{1}$, Anna Lielpētere ${ }^{1}$, Edvards Liepiñš ${ }^{1}$, \\ Sergejs Beljakovs ${ }^{1}$, Inguna Goba ${ }^{1}$ and Jānis Stradinsš ${ }^{1}$
}

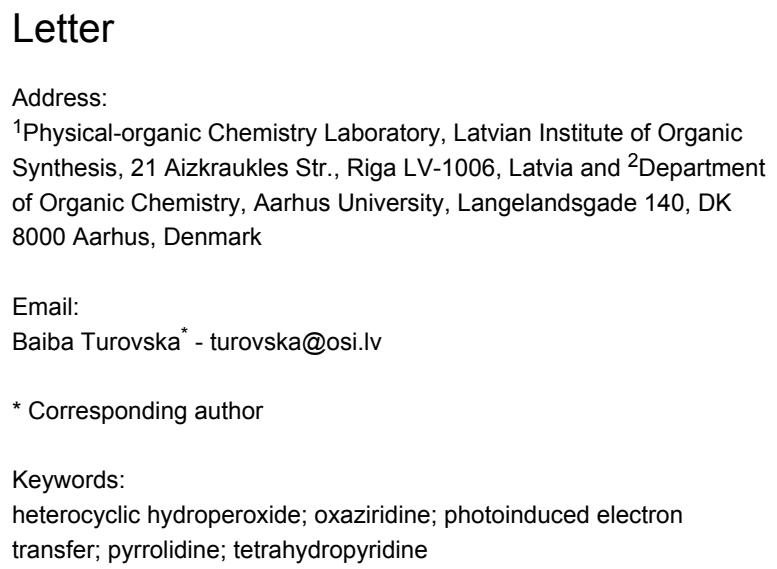

Address:

${ }^{1}$ Physical-organic Chemistry Laboratory, Latvian Institute of Organic Synthesis, 21 Aizkraukles Str., Riga LV-1006, Latvia and ${ }^{2}$ Department of Organic Chemistry, Aarhus University, Langelandsgade 140, DK 8000 Aarhus, Denmark

Email:

Baiba Turovska* - turovska@osi.lv

* Corresponding author

Keywords:

heterocyclic hydroperoxide; oxaziridine; photoinduced electron transfer; pyrrolidine; tetrahydropyridine

\author{
Beilstein J. Org. Chem. 2015, 11, 2166-2170. \\ doi:10.3762/bjoc. 11.234 \\ Received: 27 August 2015 \\ Accepted: 27 October 2015 \\ Published: 11 November 2015 \\ Associate Editor: C. Stephenson \\ (C) 2015 Turovska et al; licensee Beilstein-Institut. \\ License and terms: see end of document.
}

\begin{abstract}
Stable heterocyclic hydroperoxide can be easily prepared as a product of fast oxidation of a 1,2,3,4-tetrahydropyridine by ${ }^{3} \mathrm{O}_{2}$ if the solution is exposed to sunlight. The driving force for the photoinduced electron transfer is calculated from electrochemical and spectroscopic data. The outcome of the reaction depends on the light intensity and the concentration of $\mathrm{O}_{2}$. In the solid state the heterocyclic hydroperoxide is stable; in solution it is involved in further reactions.
\end{abstract}

\section{Introduction}

Increased attention has been paid to the chemistry of cyclic organic peroxides since it was found that naturally occurring representatives of this group possess biological activity, particular antimalarial $[1,2]$. Significantly less attention has been paid to organic aromatic or heterocyclic hydroperoxides, probably due to their low thermal stability and high reactivity.

Stable organic hydroperoxides were isolated in the early 1950s as products of autoxidation as well as catalytic oxygenation of indoles and tetrahydrocarbazoles [3-6]. In 1944 hydroperoxides were first obtained by H. Hock [7] and R. Udris [8-10] as the catalytic oxidation products of cumene. Heterocyclic hydroperoxides have been less represented, although some of these constitute the best choice for selective oxidations even in nature. When the peroxy functional group is placed near to electronegative groups, the oxidizing capability of hydroperoxides can be increased. This effect was particularly observed on heterocyclic systems.

\section{Results and Discussion}

Photosensitized aerobic oxidative aromatization [11-14] of Hantzsch 1,4-dihydropyridines has been extensively investigated, in the same time little attention has been paid to the corresponding reactions of tetrahydropyridines.

During the investigation of the electrochemical oxidation mechanism of tetrahydropyridine 1 [15], an extremely high sensitivity of the formed cation radicals towards traces of dioxygen 
was observed. In deaereated aprotic solvents 1 undergoes a reversible one-electron single-step oxidation [16] $(+1.00 \mathrm{~V}$ in $\mathrm{MeCN}$ or $+1.25 \mathrm{~V}$ in $\mathrm{CH}_{2} \mathrm{Cl}_{2}$ ) while the reversibility of the anodic process disappears immediately after the argon flow through/over the solution has been stopped (Figure 1).

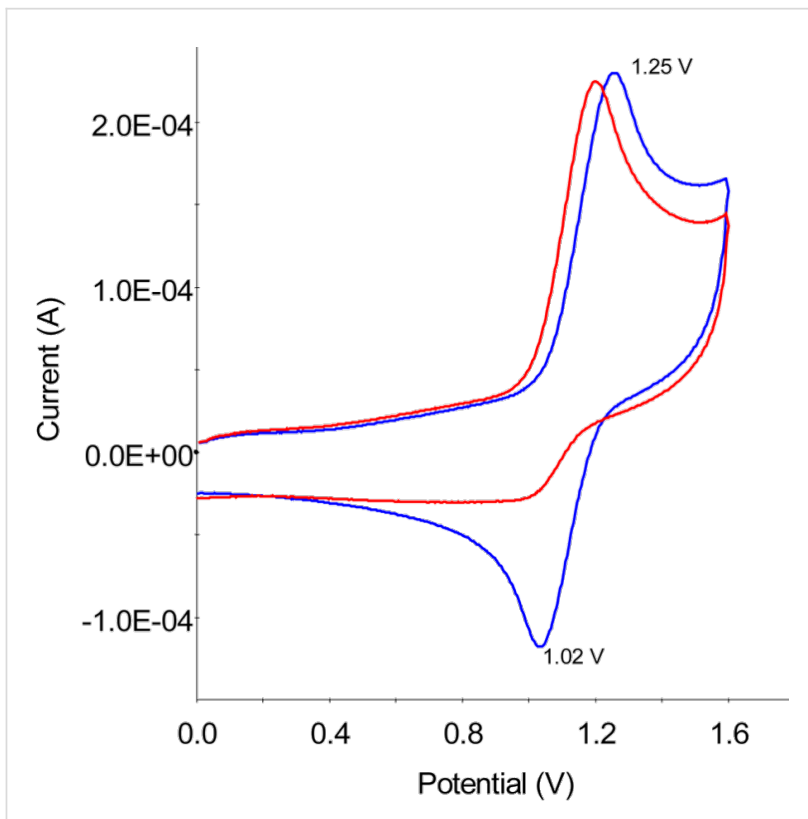

Figure 1: Electrochemical oxidation of 1 in deareated (blue) and $\mathrm{O}_{2}$ saturated (red) solutions of $\mathrm{CH}_{2} \mathrm{Cl}_{2} / 0.1 \mathrm{M} \mathrm{TBAPF}_{6}, c=5 \times 10^{-4} \mathrm{M}$.

Moreover, it was found that tetrahydropyridine 1 (Figure 2) reacts with dioxygen if the solution is exposed to intense sunlight. In order to study this reaction, the solution of $1(0.5 \mathrm{~g}$, $1.51 \mathrm{mmol})$ was left under an irradiation of intense sunlight and continuously purged with dioxygen $(\sim 9.1 \mathrm{mmol})$ [17,18] in chloroform $(25 \mathrm{~mL})$. Crystals suitable for X-ray analysis were obtained after evaporation of the chloroform by a stream of dioxygen; elemental analysis, ${ }^{1} \mathrm{H},{ }^{13} \mathrm{C}$ NMR spectra and X-ray analysis confirmed the structure of hydroperoxide 2 (Figure 2) as the only product of the reaction. Hydroperoxide $\mathbf{2}$ is a colourless crystalline compound which is stable in the solid state but unstable in solution.

The oxidation of tetrahydropyridine $\mathbf{1}$ is photoinduced; it does not take place in the dark and it depends on the intensity of the light. No reaction could be initiated by light in a deareated solution.

The reaction of dioxygen $\left({ }^{3} \mathrm{O}_{2}\right)$ having a triplet ground state with tetrahydropyridine $\mathbf{1}$ having a singlet ground state is spin forbidden. On the other hand, the electron transfer from the organic compound to ${ }^{3} \mathrm{O}_{2}$ resulting in the formation of a radical cation of the organic donor and the radical anion of $\mathrm{O}_{2}\left(\mathrm{O}_{2}^{-\bullet}\right)$ is

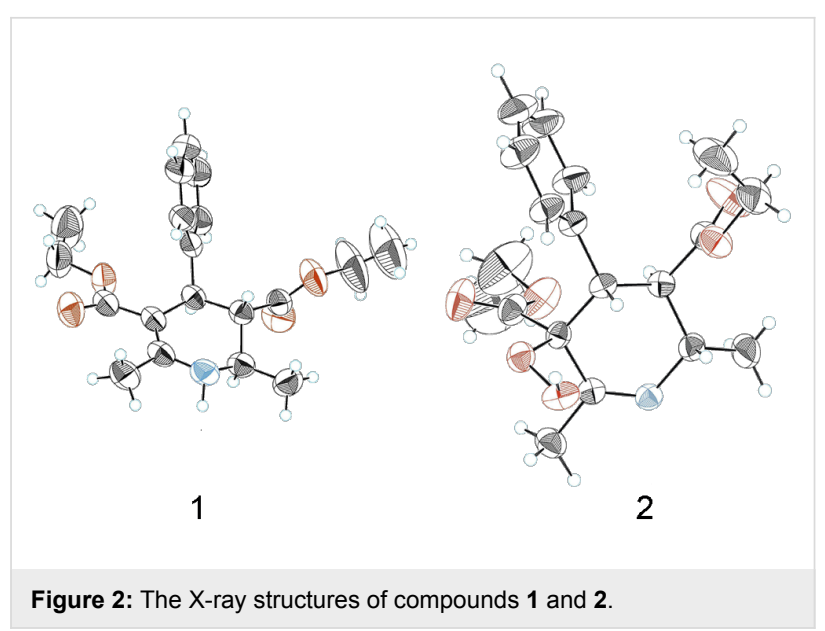

spin permitted [19], however, it is not thermodynamically favourable.

The driving force for the photoinduced electron transfer can be calculated from electrochemical and spectroscopic measurements made in the same solvent according to Weller's approximation [20]

$$
\Delta G_{\mathrm{ET}}^{0}=e\left[E_{\mathrm{ox}}^{0}(\mathrm{Do})-E_{\mathrm{red}}^{0}(\mathrm{Acc})\right]-E_{00},
$$

where $E_{\mathrm{ox}}^{0}(\mathrm{Do})-E_{\text {red }}^{0}(\mathrm{Acc})$ is the difference between the first oxidation potential of the donor and the first reduction potential of the acceptor;

$$
E_{00}=\frac{h c}{\lambda_{\max }}(\mathrm{eV})
$$

In $\mathrm{CH}_{2} \mathrm{Cl}_{2}$ the reduction potential of $\mathrm{O}_{2}$ is $-1.18 \mathrm{~V}$ and $E^{0}$ of $\mathbf{1}$ is $+1.14 \mathrm{~V}$.

$$
\begin{aligned}
\Delta G_{\mathrm{ET}}^{0} & =e[(1.14)-(-1.18)]-4.40 \\
& =2.32-4.40=-2.08 \mathrm{eV}
\end{aligned}
$$

The reaction becomes thermodynamically favourable if the organic molecule is excited to a singlet state. The oxidation potential of excited molecules is shifted to negative values $(\Delta E=\sim 2 \mathrm{~V})$ compared to their ground state [21-23]. For example the oxidation potential of 9,10-dihydro-10-methylacridine is $+0.80 \mathrm{~V}$ [23], which is shifted to $-3.10 \mathrm{~V}$ in the singlet excited state [23].

The recorded UV-vis spectrum of $\mathbf{1}$ (Figure 3 ) has only one absorption band at $\lambda_{\max }=282 \mathrm{~nm}$ in the range of $250-900 \mathrm{~nm}$ which corresponds to the spin allowed $\mathrm{S} \rightarrow \mathrm{S}^{*}$ transition $(\varepsilon=19000)$. 


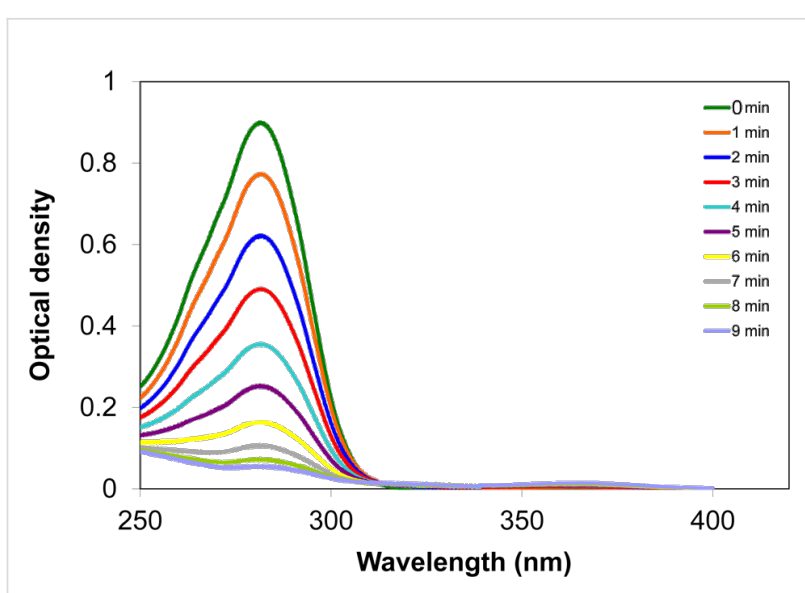

Figure 3: Decrease of the UV absorption band of compound 1 under irradiation $(254 \mathrm{~nm})$ in air-saturated $\mathrm{CHCl}_{3}, \mathrm{c}=5 \times 10^{-5} \mathrm{M}$.

If a series of UV spectra is recorded after subsequent periods of 1 min irradiation of the sample with an external UV lamp $(254 \mathrm{~nm}, 8 \mathrm{~W})$, the absorption band decreases and no new band appears in the range of 250-900 $\mathrm{nm}$ (Figure 3). If the irradiation of the sample is stopped for $1 \mathrm{~min}$, the reaction halts, and the recorded UV spectrum exactly repeats the previous one.

It might be suggested that the initiation step, excitation of $\mathbf{1}$ at $254 \mathrm{~nm}$, leading to the formation of the singlet state of $1^{*}$, is followed by single-electron transfer from $1^{*}$ to ${ }^{3} \mathrm{O}_{2}$ generating $\mathbf{1}^{+\bullet}$ and $\mathrm{O}_{2}{ }^{-}$in solution. Such reactions between strong nucleophiles and strong electrophiles, especially the annihilation reactions between ion radicals, have not been studied extensively, probably due to the difficulties of generating anion and cation radicals simultaneously [24,25].
The reactivity of superoxide is widely studied by chemists and biochemists. It has been shown electrochemically that $\mathrm{O}_{2}{ }^{-}$is a product of the reversible one-electron reduction of dioxygen in aprotic solvents [26,27]. Superoxide $\mathrm{O}_{2}^{-\bullet}$ is a highly reactive molecule $[26,28]$ and it acts as a strong Brönsted base removing a proton from substrates to an extent equivalent to that of the conjugate base with a $\mathrm{p} K_{\mathrm{a}}$ value of approximately 23 in water $[29,30]$.

A number of weakly acidic organic compounds are deprotonated efficiently in the presence of superoxide including Hantzsch 1,4-dihydropyridines [31,32]. Cation radicals have increased acidity comparing to the parent molecules from which they are derived by oxidation [33-35]. Consequently, their deprotonation proceeds more efficiently. Photooxygenation of $\mathbf{1}$ can be described as shown in Scheme 1.

In an air saturated $\mathrm{CHCl}_{3}$ solution, the concentration of dioxygen is about $2 \mathrm{mmol} / \mathrm{L}[17,18]$ and if it becomes comparable with the concentration of $\mathbf{1}$, the reaction takes a different course (Scheme 2).

It has been suggested that peracids attack the carbon-carbon double bond in enamines to give the corresponding epoxides, however, in most cases they have not been isolated [36].

The hydroperoxide 2 reacts in the same way. Fission of the epoxide ring may be induced by the base itself producing $\mathbf{3}$. Attack of a second molecule of hydroperoxide $\mathbf{2}$ on the imine group of $\mathbf{3}$ oxidizes it to oxaziridine intermediate 4 (Figure 4), which then undergoes a slow nucleophilic ring fission followed by cyclization (Scheme 3) to give 5 (Figure 4 ).

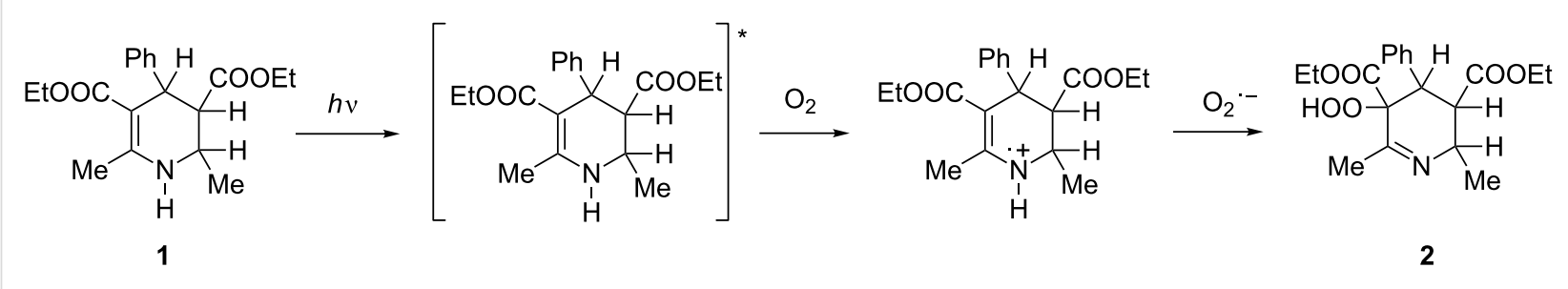

Scheme 1: Photoinduced reaction of 1 in $\mathrm{O}_{2}$ saturated $\mathrm{CHCl}_{3}$ under irradiation by intensive sunlight.

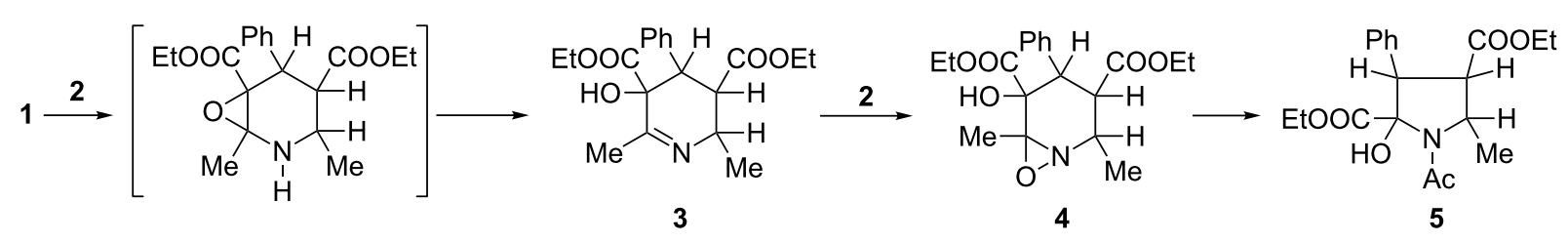




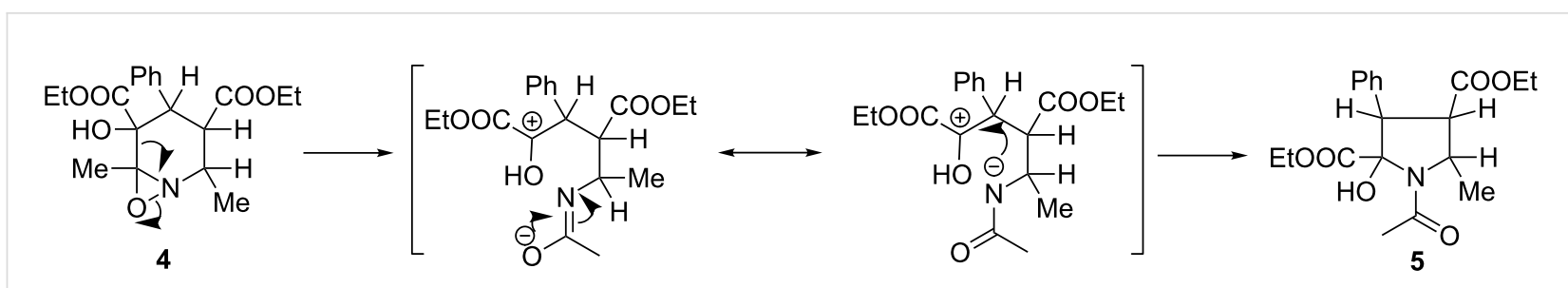

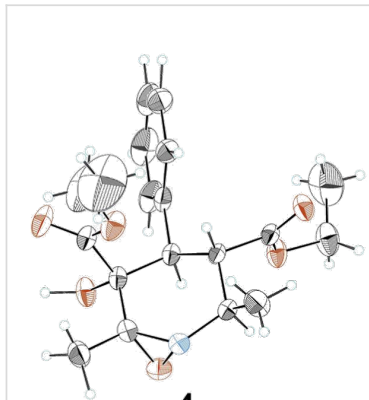

4

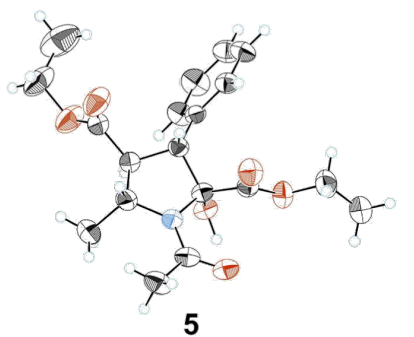

5
Figure 4: The X-ray structures of compounds 4 and 5.

The reaction depicted in Scheme 2 proceeds as long as the hydroperoxide $\mathbf{2}$ is present in the solution, and the crude product contains the mixture of $\mathbf{3}, \mathbf{4}$ and $\mathbf{5}$. The same product mixture was obtained if the solution of $\mathbf{1}$ is treated with concentrated $\mathrm{H}_{2} \mathrm{O}_{2}$ or Fenton reagent.

The reaction starts even if the irradiation wavelengths only partially cover the absorption band of $\mathbf{1}$. It explains also the observed fact that during the summer as well as under bright laboratory light the photooxygenation of tetrahydropyridine $\mathbf{1}$ in the presence of dioxygen proceeds spontaneously in $\mathrm{CHCl}_{3}$, $\mathrm{CH}_{2} \mathrm{Cl}_{2}$ or $\mathrm{CH}_{3} \mathrm{CN}$ solutions. Although much of the light emitted by the sun in UV below $300 \mathrm{~nm}$ is absorbed by ordinary glass, the transmitted intensity of the sunlight in summer at $300 \mathrm{~nm}$ is sufficient to initiate the photooxygenation of $\mathbf{1}$.

Direct reactions of dioxygen with organic substrates in the absence of a catalyst are usually slow, unless the substrate is a particularly good reducing agent. Excited state species are easier to oxidize than the corresponding ground state species.

The reaction between photochemically generated radical cations and radical anions by electron transfer from photoexcited electron donor to electron acceptors is often reversible [37] thus reproducing the reactant pair without the formation of a chemical bond. As the dioxygen has a large reorganization energy for electron transfer [38,39], the reverse reaction may be retarded, promoting to the subsequent heterocycle conversions.

\section{Conclusion}

Several synthetic routes have been explored towards chiral hydroperoxides as they have been utilized successfully in a variety of asymmetric oxidations. We have found a sunlight activated reaction of 1,2,3,4-tetrahydropiridine with dioxygen $\left({ }^{3} \mathrm{O}_{2}\right)$ producing stable heterocyclic hydroperoxide in excellent yield. The reaction has significant advantages as it uses costfree reagents: light and dioxygen. The same reaction demonstrated the oxidizing capacity of the hydroperoxide when its concentration is less or comparable with the tetrahydropyridine leading to another versatile intermediate in organic synthesis oxaziridine - as the inherent strain of the ring and the relatively weak $\mathrm{N}-\mathrm{O}$ bond makes it unusually reactive.

\section{Supporting Information}

Synthesis and characterization of all products, copies of ${ }^{1} \mathrm{H}$ and ${ }^{13} \mathrm{C}$ NMR spectra of newly synthesized products.

\section{Supporting Information File 1}

Experimental and analytical data.

[http://www.beilstein-journals.org/bjoc/content/ supplementary/1860-5397-11-234-S1.pdf]

\section{Acknowledgements}

This research was supported by the European Regional Development Fund (ERDF), project Nr. 2DP/2.1.1.1.0/14/APIA/ VIAA/060.

\section{References}

1. Gesmundo, N. J.; Nicewicz, D. A. Beilstein J. Org. Chem. 2014, 10, 1272-1281. doi:10.3762/bjoc. 10.128

2. Terent'ev, A. O.; Borisov, D. A.; Vil', V. A.; Dembitsky, V. M. Beilstein J. Org. Chem. 2014, 10, 34-114. doi:10.3762/bjoc.10.6

3. Witkop, B.; Patrick, J. B. J. Am. Chem. Soc. 1951, 73, 2188-2195. doi:10.1021/ja01149a079

4. Witkop, B.; Patrick, J. B. J. Am. Chem. Soc. 1951, 73, 2196-2200. doi:10.1021/ja01149a080

5. Witkop, B.; Patrick, J. B.; Rosenblum, M. J. Am. Chem. Soc. 1951, 73, 2641-2647. doi:10.1021/ja01150a065 
6. Mentel, M.; Breinbauer, R. Curr. Org. Chem. 2007, 11, 159-176. doi:10.2174/138527207779316426

7. Hock, H.; Lang, S. Ber. Dtsch. Chem. Ges. B 1944, 77, 257-264. doi:10.1002/cber.19440770321

8. Stradiņš, J. P. Iz istorii estestvoznanija i techniki Pribaltiki; Zinatne: Riga, Latvia, 1968.

9. Udris, R. J.; Sergeyev, P. G.; Kruzhalov, B. D. Author's certificate of USSR No. 106666, January 7, 1947.

10. Udris, R. J.; Kruzhalov, B. D.; Sergeyev, P. G. Author's certificate of USSR No. 106712, January 7, 1947.

11. Memarian, H. R.; Abdoli-Senejani, M.; Tangestaninejad, S. J. Iran. Chem. Soc. 2006, 3, 285-292. doi:10.1007/BF03247221

12. Han, B.; Liu, Z.; Liu, Q.; Yang, L.; Liu, Z.-L.; Yu, W. Tetrahedron 2006, 62, 2492-2496. doi:10.1016/j.tet.2005.12.056

13. Pizarro, N.; Günther, G.; Núñez-Vergara, L. J. J. Photochem. Photobiol., A 2007, 189, 23-29. doi:10.1016/j.jphotochem.2007.01.003

14. Memarian, H. R.; Abdoli-Senejani, M. Ultrason. Sonochem. 2008, 15, 110-114. doi:10.1016/j.ultsonch.2006.06.008

15. Rosentreter, U. Synthesis 1985, 210-212. doi:10.1055/s-1985-31160

16. Turovska, B.; Goba, I.; Lielpetere, A.; Turovskis, I.; Lusis, V.; Muceniece, D.; Stradinš, J. Chem. Heterocycl. Compd. 2014, 49, 1640-1652. doi:10.1007/s10593-014-1415-5

17. Hara, M.; Samori, S.; Xichen, C.; Fujitsuka, M.; Majima, T. J. Org. Chem. 2005, 70, 4370-4374. doi:10.1021/jo050317n

18. Hanaki, H.; Fukatsu, Y.; Harada, M.; Sawaki, Y. Tetrahedron Lett. 2004, 45, 5791-5793. doi:10.1016/j.tetlet.2004.06.022

19. Fukuzumi, S.; Okamoto, K.; Tokuda, Y.; Gros, C. P.; Guilard, R. J. Am. Chem. Soc. 2004, 126, 17059-17066. doi:10.1021/ja046422g

20. Rehm, D.; Weller, A. Isr. J. Chem. 1970, 8, 259-271. doi:10.1002/ijch.197000029

21. Qin, C.; Clark, A. E. Chem. Phys. Lett. 2007, 438, 26-30. doi:10.1016/j.cplett.2007.02.063

22. Rubio, N.; Jiménez-Banzo, A.; Torres, T.; Nonell, S. J. Photochem. Photobiol., A 2007, 185, 214-219. doi:10.1016/j.jphotochem.2006.06.007

23. Fukuzumi, S.; Ishikawa, M.; Tanaka, T. J. Chem. Soc., Perkin Trans. 2 1989, 1037-1045. doi:10.1039/P29890001037

24. Amatore, C.; Brown, A. R. J. Am. Chem. Soc. 1996, 118, 1482-1486. doi:10.1021/ja952600h

25. Mayeda, E. A.; Bard, A. J. J. Am. Chem. Soc. 1973, 95, 6223-6226. doi:10.1021/ja00800a012

26. Sawyer, D. T.; Chiericato, G., Jr.; Angelis, C. T.; Nanni, E. J., Jr.; Tsuchiya, T. Anal. Chem. 1982, 54, 1720-1724. doi:10.1021/ac00248a014

27. Maricle, D. L.; Hodgson, W. G. Anal. Chem. 1965, 37, 1562-1565. doi:10.1021/ac60231a027

28. Meskina, M. Y.; Baider, L. M.; Skibida, I. P. Bull. Acad. Sci. USSR, Div. Chem. Sci. (Engl. Transl.) 1990, 39, 646-650. doi:10.1007/BF00960318

29. Frimer, A. A.; Farkash-Solomon, T.; Aljadeff, G. J. Org. Chem. 1986, 51, 2093-2098. doi:10.1021/jo00361a030

30. Sawyer, D. T.; Gibian, M. J. Tetrahedron 1979, 35, 1471-1481. doi:10.1016/0040-4020(79)80032-0

31. Ortiz, M. E.; Núñez-Vergara, L. J.; Camargo, C.; Squella, J. A. Pharm. Res. 2004, 21, 428-435. doi:10.1023/B:PHAM.0000019295.32103.e4

32. Ortiz, M. E.; Núñez-Vergara, L. J.; Squella, J. A. J. Electroanal. Chem. 2002, 519, 46-52. doi:10.1016/S0022-0728(01)00720-3
33. Anne, A.; Fraoua, S.; Hapiot, P.; Moiroux, J.; Saveant, J.-M. J. Am. Chem. Soc. 1995, 117, 7412-7421. doi:10.1021/ja00133a014 34. Hapiot, P.; Moiroux, J.; Saveant, J. M. J. Am. Chem. Soc. 1990, 112, 1337-1343. doi:10.1021/ja00160a007

35. Anne, A.; Moiroux, J. Can. J. Chem. 1995, 73, 531-538. doi:10.1139/v95-068

36. Pitacco, G.; Valentin, E. In The Chemistry of Enamines; Rappoport, Z., Ed.; John Wiley \& Sons, Ltd.: NY, USA, 1994.

37. Ohkubo, K.; Nanjo, T.; Fukuzumi, S. Bull. Chem. Soc. Jpn. 2006, 79, 1489-1500. doi:10.1246/bcsj.79.1489

38. Lind, J.; Shen, X.; Merenyi, G.; Jonsson, B. O. J. Am. Chem. Soc. 1989, 111, 7654-7655. doi:10.1021/ja00201a078

39. Eberson, L.; Gonzalez-Luque, R.; Lorentzon, J.; Merchan, M.; Roos, B. O. J. Am. Chem. Soc. 1993, 115, 2898-2902. doi:10.1021/ja00060a043

\section{License and Terms}

This is an Open Access article under the terms of the Creative Commons Attribution License

(http://creativecommons.org/licenses/by/2.0), which permits unrestricted use, distribution, and reproduction in any medium, provided the original work is properly cited.

The license is subject to the Beilstein Journal of Organic Chemistry terms and conditions: (http://www.beilstein-journals.org/bjoc)

The definitive version of this article is the electronic one which can be found at: doi:10.3762/bjoc. 11.234 